\title{
Application Experience of the AHP for the Antarctic Issues
}

$\underline{\text { Oleksandr Kuzko', }}{ }^{1}$ Mykola Leonov ${ }^{2}$

${ }^{1}$ Self-employed, Kyiv, Ukraine, uackuzko@ukr.net

${ }^{2}$ State Institution National Antarctic Scientific Center of Ukraine

Investigation is devoted to the application of the Analytic Hierarchy Process (AHP) [1] to obtain solutions for current challenges in such important areas of the decision-making as the activity both in Antarctic and in Antarctic Treaty System.

The aim of the study - share the experience of using AHP to obtain quantitative characteristics both Antarctic values and threats and National interests of Ukraine in both Antarctica and in Antarctic Treaty System.

It is important for:

- planning the financial, material and human resources for the effective implementation of the Ukraine's Antarctic Programs and the Ukraine's international obligations related to the membership in the Antarctic Treaty;

- development recommendations for the policy-makers and stakeholders relating to Ukraine's activities in Antarctica and in the Antarctic Treaty System;

- informing the general public about the Ukraine's efforts and activities in Antarctica and in the Antarctic Treaty System.

Owing to the human activity increasing in Antarctica the need has been arose in cataloguing the range of values human beings place in Antarctica and in the explaining the importance of each value or category of values.

To answer the arising questions in 2010 the Social Science Action Group (SSAG) of Scientific Committee on Antarctic Research (SCAR) in Antarctic Treaty System has been established [2].

The SSAG has pre-formed categories of such six values:

1. Environmental,

2. Societal,

3. Economic,

4. Scientific,

5. Aesthetic, and

6. Political,

which are used in this investigation.

In 2007 Johannes Huber, Executive Secretary of the Antarctic Treaty Secretariat in Lecture in National Antarctic Scientific Center of Ukraine [3] has formulated threats for Antarctica:

1. Global warming,

2. Tourism,

3. Legal Status, 
4. Alien species,

5. Energy crisis,

6. Non-Party States,

which also are used in this investigation.

According to AHP at Stage 1 two corresponding matrixes were created [4] with the lists of the above-mentioned Antarctic values and threats as of 2011.

At Stage 2 pairwise comparison of the values and threes was carried out by importance ranking. The matrixes with the lists of values and threats were filled with pairwise comparisons with compliance the consistent conditions.

At Stage 3 eigenvalues (quantitative characteristics) were obtained of the prepared matrixes, which are listed below after the normalization procedure:

\begin{tabular}{|c|c|c|}
\hline Antarctic Values & Quantitative characteristics & Ranks \\
\hline Environmental & 0,45 & 1 \\
\hline Economic & 0,20 & 3 \\
\hline Political & 0,16 & 4 \\
\hline Scientific & 0,11 & 5 \\
\hline Societal & 0,06 & 6 \\
\hline Aesthetic & 0,02 & \\
\hline
\end{tabular}

\begin{tabular}{|c|c|c|}
\hline Antarctic Threats & Quantitative characteristics & Quantitative characteristics \\
\hline Global warming & 0,41 & 1 \\
\hline Non-Party States & 0,20 & 2 \\
\hline Tourism & 0,15 & 4 \\
\hline Alien species & 0,10 & 5 \\
\hline Energy crisis & 0,08 & 6 \\
\hline Legal Status & 0,07 & \\
\hline
\end{tabular}

The obtained quantitative characteristics make it possible to systematize both the Antarctic values and threats in the importance ranking. 
The findings might be useful for decision-making in managing human activities within the Antarctic Treaty System at the both national and international levels.

The findings seem important to inform wide public about priority of activities in Antarctica as well as to get public support for further management actions.

The findings might also stimulate further research on improvement of the categories of Antarctic values and threats and of their rankings algorithms.

To obtain quantitative characteristics of the Ukraine's national interests in Antarctica, the Antarctica universal values, established by SSAG [2], were used.

Similarly, according to AHP:

- the matrix with the corresponding list of SSAG categories was created;

- carried out pairwise comparison of categories and filling the matrix with expert assessments with compliance the consistent conditions;

- carried out the eigenvalues calculation of the resulting matrix and the normalization procedure of the obtained eigenvalues.

The corresponding quantitative characteristics of the Ukraine's national interests are given below in the order established by SSAG [5].

\begin{tabular}{|c|c|c|}
\hline $\begin{array}{c}\text { Ukraine's national interests } \\
\text { in Antarctica and in } \\
\text { Antarctic Treaty System }\end{array}$ & Quantitative characteristics & Ranks \\
\hline Environmental & 0,12 & 4 \\
\hline Societal & 0,7 & 3 \\
\hline Economic & 0,16 & 1 \\
\hline Scientific & 0,44 & 6 \\
\hline Aesthetic & 0,3 & 2 \\
\hline Political & 0,18 & \\
\hline
\end{tabular}

The obtained results serve as analytical basis for political decision-making by executive authorities concerning Ukraine's activity in Antarctica for near-term outlook and beyond, and also for substantiation of the Ukraine's political position in Antarctic Treaty System.

The AHP is also offered for quantitative analysis of the national interests of all Antarctic Treaty Parties as the International Standard .

Thus, the quantitative characteristics of the national interests of the Antarctic Treaty Parties in the order determined by the SCAR Working Group on Social Sciences, can be systematized by analogy with the systematization of the optical spectrums of stars in astrophysics.

Then the total cost of Antarctic activities of each Antarctic Treaty Party can serve as a general indicator of the importance of Antarctica for each Party (similar to the brightness of the stars in astrophysics). 
Such the systematization can be, for example, an additional basis for determining the amount of annual membership fees of the Antarctic Treaty Parties in the Antarctic Treaty System institutions.

\section{References}

1. Saaty T.L. Decision making with the analytic hierarchy process, Int. J. Services Sciences, 2008. Vol. 1, No. 1, PP. 83-98.

2. http://www.scar.org/researchgroups/via .

3. Johannes Huber, Executive Secretary of the Antarctic Treaty Secretariat. Lecture in National Antarctic Scientific Center of Ukraine, 2007.

4. Kuzko O., Leonov M., Savchenko V., Fedchuk A. Quantitative Characteristics of Values in Antarctica and Threats for Antarctica.// Proceedings of the XXXIISCAR Open Science Conference "Antarctic Science and Policy Advice in a Changing World” (July/ 13-25/ 2012, Portland, USA). - Portland: State University, 2012. - Abstract № 46.

5. Kuzko O., Savchenko V., Fedchuk A. Application of Hierarchy Research Method for Assessment of National Interests in Antarctica // Book of Abstracts of the SCAR Workshop "Past, present and future of human connections to the Antarctic", (1-5 July 2013, Cambridge, UK) - Cambridge: British Antarctic Survey.- 2013.- P. 16. 